\title{
0 menor e o maior no cinema pessoal: Diário de uma busca, Elena e Mataram meu irmão
}

\section{Roberta Veiga}

\section{Resumo}

É possível que o cinema de escrita pessoal, dedicado a uma história de vida menor, doméstica, familiar, evoque outra, maior, coletiva, de um tempo? 0 artigo nasce do interesse em compreender de que modo o cinema de acento autobiográfico pode fazer pensar a natureza alter do eu, ou seja, a incorporação do outro, do mundo e da história na constituição de um si. A partir do tensionamento entre um desejo subjetivo de construção de si e os encontros que caracterizam o documentário, elegemos três filmes recentes cujos projetos se assemelham: Diário de uma busca (2011), Elena (2012) e Mataram meu irmão (2013). Nos três, os cineastas lidam com a morte de um parente próximo e realizam, cada um a seu modo, o trabalho de elaboração dessas mortes, de forma a fazer do processo de filmagem uma busca no presente por um acontecimento passado.

\section{Palavras-Chave}

Cinema de escrita pessoal. Arquivo. Alteridade. História. Documentário de busca.

Roberta Veiga | roveigadevolta@gmail.com Doutora em Comunicação Social pela Universidade Federal de Minas Gerais - UFMG

Professora do Programa de Pós-graduação em Comunicação da Universidade Federal de Minas Gerais - UFMG.
Nesses últimos anos, a produção brasileira de filmes feitos em primeira pessoa, de forte acento confessional e memorialístico, se tornou mais expressiva. Dentre eles, grande parte se volta para as relações familiares, como, por exemplo, Diário de uma busca, de Flávia Castro (2011); Os dias com ele, de Maria Clara Escobar (2012); Elena, de Petra Costa (2012); Otto, de Cao Guimarães (2012); Vento de Valls, de Pablo Lobato (2013); Mataram meu irmão, de Cristiano Burlan (2013); Já visto jamais visto (2013), de Andrea Tonacci ${ }^{1}$.

0 interesse de nossa pesquisa tem sido 0 de compreender de que modo esse cinema de escrita pessoal e traço familiar faria pensar a natureza alter do eu, ou seja, a incorporação do outro, do mundo e da história na constituição de um si. Em um primeiro recorte, propomos extrair de alguns desses filmes os mecanismos dos quais lançam mão para promover a fusão e/ou o tensionamento entre um projeto pessoal, um desejo subjetivo de construção de si (com suas ficcionalizações), e o cometimento de um filme documentário que, na concepção de Comolli, "só pode se construir em friç̧ão com o mundo" (2008, 
p. 173)2 . Jean-Claude Bernardet (2005) chamou o movimento por meio do qual o realizador documenta seu processo de busca por um "objeto" pessoal e, dessa forma, coloca em relação 0 gesto autobiográfico e 0 gesto documental, de "documentário de busca". Na ocasião, Bernardet abordava os filmes Passaporte Húngaro, de 2003 (no qual o projeto da cineasta Sandra Kogut é obter a nacionalidade e o passaporte húngaro), e 33, de 2002 (no qual o cineasta Kiko Goifman pretende encontrar a mãe biológica), a partir não de uma análise fílmica, mas sim do entendimento dos processos de trabalho dos diretores. A preocupação do autor tinha origem na compreensão de que os dois projetos partiam de um alvo preciso que poderia ou não ser atingido, gerando então uma imprevisibilidade. Contudo, o pesquisador se perguntava sobre como manter, no momento da montagem, essa imprevisibilidade que faz da filmagem uma documentação do processo, uma vez que as incógnitas e 0 suspense já se dissolveram.

Pensando, junto com Bernardet, a dimensão processual desses filmes, porém guiados não pela mesma pergunta, mas pela imbricação entre uma história pessoal e uma história maior, bem como pela relação temporal que conforma a mesma, elegemos três produções recentes cujos projetos se assemelham: Diário de uma busca, Elena e

Mataram meu irmão. Nos três longas, os cineastas lidam com a morte de um parente próximo: o pai de Flávia Castro, a irmã de Petra Costa e 0 irmão de Cristiano Burlan. Cada um a seu modo, esses filmes realizam um trabalho de elaboração dessas mortes de forma que o processo de filmagem se torne uma busca pessoal no presente por algo que está no passado, ou seja, trata-se da experiência de retomar, através do cinema, a experiência da morte de um ente muito próximo.

Três perguntas nos movem para entender 0 mecanismo cinematográfico que resulta dessa experiência. A primeira concerne ao processo mesmo do filme: como tornar presente na ação filmica uma matéria biográfica que reside no passado? Como pôr em cena a memória e a busca por algo que "já não é mais", uma situação de morte? A segunda pergunta, já anunciada, é um afunilamento da primeira na medida em que diz respeito às condições de atualização dessa memória pra que haja filme: de que maneira esses cineastas se encenam ao encenarem as relações com seus parentes mortos? E, por fim, a terceira, e mais ampla questão, lida com o manejo do passado, e a relação com o outro, em uma escala histórica: é possível que 0 cinema de escrita pessoal, dedicado

Além dos longas citados, destacamos ainda alguns curtas importantes que se inserem nessa mesma caracterização geral: Mauro em Caiena, de Leonardo Mouramateus (2012); Tigre, de João Borges; Memória da memória, da Paula Gaitán (os dois últimos de 2013).

Ainda segundo Comolli, o cinema documentário é o cinema como práxis que, longe das duras roteirizações promovidas pelo espetáculo, leva em conta o desejo do outro, sujeito e mundo filmado, e em uma relação que parte da diferença entre quem filma e quem é filmado só pode se dar no encontro com o outro (COMOLLI: 2008). 
a uma história de vida menor, doméstica, familiar, evoque outra, maior, coletiva, de um tempo? Se sim, que formas de passagem do menor para o maior estão em jogo? As perguntas mobilizam três grandes figuras que se entrelaçam: a temporalidade, a alteridade e a história. Tais figuras são identificadas a partir de elementos cinematográficos que se apresentam no filme como condição de possibilidade material para a conformação das mesmas e funcionam analiticamente.

Em Diário de uma busca, Flávia Castro parte para 0 filme com intuito de investigar a situação misteriosa da morte do pai, Celso, em 1984, um militante de esquerda, que foi exilado durante a ditadura e passou pelo Chile, Argentina, Venezuela e França. Já que o trabalho da diretora é uma arqueologia, uma volta ao passado (é lá que o pai existe e lá que foi morto), a investigação, a busca pela história do pai, é a ação que a mantém no presente para que haja filme. Em um movimento que precisa alinhavar tempos, figurar memórias, o processo de Flávia se desdobra em quatro camadas que se atravessam: 1) a manipulação de fotos, documentos, cartas e gravações de arquivos (domésticos e institucionais);

2) a reconstituição de caminhos e paradas (0 retorno às cidades e lugares onde esteve no exílio, a criação de cenas nas quais essa experiência é evocada); 3) as entrevistas com parentes e amigos da família; e 4) na última camada, que perpassa as outras três, 0 relato em off da cineasta de suas memórias de criança e adolescente, e dos acontecimentos da época, em um tom muitas vezes confessional (ao modo de um diário).
Em Elena, Petra Costa irá rememorar a morte da irmã através de uma reconstituição que se define fortemente pela mise-en-scène da própria cineasta. Elena suicidou-se em 1990, com 20 anos, na cidade de Nova York, onde fora morar com a mãe e Petra ainda criança, com o intuito de dar continuidade a seus estudos de teatro. Para se aproximar desse acontecimento, vinte e três anos depois, a cineasta volta a Nova York, e irá encenar uma busca pela irmã. Já de início estamos na cena de reconhecimento, aquela que define uma ambiência para o filme, e que sempre retorna, na qual Petra anda pelas ruas da cidade como se estivesse à procura de Elena, ao mesmo tempo em que sua voz off encena uma comunicaçãa imaginária com a irmã, simulando uma narrativa epistolar. Assim como em Diário de uma busca, o filme pode ser visto em camadas que irão figurar no presente do filme, o passado e as memórias: 1) os arquivos, 2) as entrevistas, 3) as revisitações, 4) 0 off constante; e, também, 5) as encenações da diretora e de outros personagens.

Menos ambicioso do que um projeto de investigação das circunstâncias oficiais da morte do irmão, e menos pessoal do que uma reconstituição marcada pela auto-mise-enscène, em Mataram meu irmão, o retorno à experiência passada - 0 assassinato de Rafael Burlan, em 2001, em Capão Redondo, periferia de São Paulo - se faz não por dentro, por uma expressão interior que se manifeste durante todo o filme, mas pelas bordas. Mataram meu irmão é, predominantemente, constituído de entrevistas 
com os parentes e amigos da família, e a voz off do cineasta é uma manifestação pontual. Enquanto o material de arquivo de Flávia e Petra é fundante das figurações da memória, e, em sua extensão e heterogeneidade, preenche todo filme de fotografias, vídeos, gravações e textos escritos (anotações, cartas e diários), no filme de Cristiano Burlan o uso do arquivo é fortemente restrito, e a composição das imagens, que intercalam as entrevistas (as ruas da periferia, as 'quebradas', os espaços vazios das casas), é enxuta.

\section{Temporalidade ou as potências do arquivo}

No filme Diário de uma busca, os arquivos institucionais constituem um eixo narrativo estruturante do filme: a investigação da morte do pai. Mais do que vestígios de uma vida passada, são registros (documentos, matérias de jornais, fotos) de um crime que envolveu militantes de esquerda, ex-guerrilheiros, um nazista, em um país recém-saído da ditadura. Por outro lado, 0 álbum de família se insere no eixo memorialístico do filme dando contorno ao rosto de Celso em diversas idades, enquanto os textos e as imagens das cartas que ele deixou expressam seu pensamento em diferentes fases.

Em Elena, apenas um laudo médico, que descreve em inglês o suicídio como a causa mortis da jovem, funciona como o registro "oficial" do acontecimento. A maioria dos outros materiais provenientes de arquivo institucional (cenas da jovem dançando na Companhia de Teatro Boi Voador, matérias de jornal sobre a peça), assim como os arquivos de família, está ali para preencher de carne e vida a figura de Elena. No caso de Mataram meu irmão, um único material proveniente de arquivo institucional cumpre essa dupla função: 0 vestígio de um passado que registra e atesta sua verdade, evidências do crime, e o preenchimento indicial da figura de Rafael até então só presente nos depoimentos.

Se em Diário de uma busca, a violência da morte do pai vem se somar à do arquivo, que reserva a ela 0 lugar do fato policial, das manchetes dos jornais'; em Mataram meu irmão, esse lugar é mais opressor, uma vez que só vemos nitidamente a imagem de Rafael, presa ali, nas fotos que ilustram o registro da polícia. Em uma sequência de oito fotos, o corpo da vítima aparece em várias posições, acompanhado de legendas técnicas que identificam as perfurações dos tiros, enquanto ouvimos o que parece ser o barulho de uma máquina de laminar. Na última, a "foto identificadora" do corpo da vítima, divisamos o rosto de Rafael de olhos cerrados.

Através dos arquivos domésticos, imagens de Celso e Elena aparecem em profusão compondo 
a narrativa de suas vidas. Em diversos lugares onde esteve durante 0 exílio, sorrindo para a câmera, abraçando a esposa, fumando seu charuto, segurando a filha no colo, o pai aparece em fotos tiradas em família. Conversando com a mãe, brincando com a babá, dançando com o pai, balançando a irmã no colo, Elena aparece em voz e gestos nos vídeos caseiros. Já a figura de Rafael irmão, marido, sobrinho, amigo (com exceção de uma única foto familiar pouco nítida) só poderá ser construída pelos depoimentos, reservando à força indicial da imagem de tornar presente um ausente para um único lugar: a de um rapaz morto na periferia de São Paulo fotografado por peritos para fins de um laudo policial.

Se em Diário de uma busca e Elena a separação entre a vida e a morte está presente tanto para os mortos quanto para os vivos, em Mataram meu irmão, Rafael tem sua vida indissociável de sua morte, e Cristiano só existe nessa indissociabilidade. Flávia e Petra constroem uma narrativa cronológica que desenha uma curva dramática descendente: da vida, e do entusiasmo por ela, à depressão e à morte. Elena, em seu afã de ser atriz de Hollywood, vai pra Nova York em busca do seu sonho artístico. Celso, em seu desejo revolucionário, sai do país pra viver a militância em busca de seu sonho político. Ambos são vencidos por algo maior do que eles. Em Mataram meu irmão não há curva, mas um emaranhado de relações familiares cravado no corroído tecido social de uma metrópole brasileira na qual a morte, e a experiência que 0 cineasta faz dela, é 0 epicentro.
Os arquivos domésticos em Elena são, em sua maioria, vídeos feitos em família, enquanto em Diário de uma busca as fotografias prevalecem. Essa diferença de suportes marca uma relação com a imagem também diversa. Petra cresce na mira da câmera de vídeo, muitas vezes manipulada por Elena que a dirige, ou pela mãe que as filma. Na maioria das cenas, elas interpretam deliberadamente para a câmera e chegam a fazer um pequeno filme de ficção no qual assassinam a babá. Elena expõe sua relação com a câmera, diz que filma de improviso, e movimenta 0 aparelho para "dançar com a lua". No uso desses vídeos caseiros, Petra não apenas revive sua relação com a irmã, mas explicita uma passagem direta entre vida e performance que poderia, no limite, resultar em um metadiscurso sobre a própria Elena.

Flávia faz parte de uma geração que guardava as fotografias em álbuns. Apesar da singularidade das fotos, originária de uma biografia particular, elas exprimem algo que é comum a todos: 0 nascimento, a infância, as brincadeiras, a antiga casa, as festas e os rituais. Os momentos fixos nas fotos são como rastros que, para lembrar Benjamin (2006), em um movimento paradoxal similar ao da experiência aurática, tornam acontecimentos menores, distantes no tempo e no espaço, quase tangíveis que destacam, em sua espontaneidade, uma qualidade daquelas vivências".

Em Elena, com algumas exceções, os vídeos caseiros parecem já marcados por atos performáticos que antecipam o imaginário 
feminino construído pelo filme, que é preenchido pelo desejo de ficção daquelas mulheres. Além de todo o esforço de Elena em se tornar atriz no cinema norte-americano e "filmar com Coppola", e da forte opção de Petra pela encenação, não apenas de si mesma, mas também da irmã, a mãe, que protagonizou um curta nos anos 60, também sonhava em atuar nos filmes de Hollywood "ao lado de Frank Sinatra". Parece que aqui o filme de família tradicional (esse capturado pelos arquivos) ${ }^{5}$ já está contaminado por uma força própria ao espetáculo que o filme de Petra, ao retomar, não pretende pôr em perspectiva, nem se curvar sobre, no intuito de produzir com a dobra uma reflexividade, um pensamento ou ação sobre 0 próprio espetáculo.

Apesar do tom melancólico do filme, o trabalho com os arquivos de família, conjugado aos textos em off, principalmente na primeira parte de Elena, bem como o eixo memorialístico de Diário de uma busca são potentes em fazer aparecer a figura do pai ausente e de Flávia, da irmã ausente e de Petra, aproximando o passado menos pela morte do que pelo vitalismo de uma vida pela militância e pela performance.
Em Mataram meu irmão, há apenas uma foto de família amarelada, cheia de borrões, sem nitidez, e sua potência reside justamente no contrário: na impossibilidade de reviver o irmão pela e na imagem, na impossibilidade de dissociar vida e morte. Em uma praia, vemos três garotos abraçados saindo do mar. Em off, Cristiano conversa ao telefone sobre Rafael com o outro irmão que está em uma penitenciária em Cuiabá. Rasurados e desfocados, tentamos com dificuldade ver os rostos dos três, enquanto o irmão preso lembra que Rafael era uma pessoa bonita, conta algo do envolvimento dele com drogas e com o tráfico, e confessa que, apesar do calor e de dividir uma cela com nove homens, está bem de saúde. Ali, a imagem do passado é incapaz de fazer sobreviver à qualidade daquela vida naquele cenário feliz de infância, mas apenas atesta com suas marcas a experiência presente, a separação entre os irmãos: a morte, a prisão, o filme (ou melhor, um distanciamento que o filme não nega). Essa única fotografia aponta para uma outra dimensão paradoxal do rastro, que parece negar a primeira em seu movimento de tornar presente uma ausência. 0 rastro, nesse caso, é menos a convocação do que 0 apagamento do passado, é mais ausência do que presença do distante. Entretanto, não há, de fato, uma negação

"Rastro e aura. 0 rastro é a aparição de uma proximidade, por mais longínquo que esteja aquilo que o deixou. A aura é a aparição de algo longínquo, por mais próximo que esteja aquilo que a evoca. № rastro, apoderamo-nos da coisa; na aura, ela se apodera de nós" (BENJAMIN, 2006, p. 490).

Lembramos aqui da exposição "Salvem os filmes amadores: inventários, apostas, problemas", de Roger Odin, no XVII Encontro Internacional SOCINE, em 08 de outubro de 2013, na UNISUL (Florianópolis, SC), na qual apresentou uma tipologia dos filmes amadores, identificando o filme de família "tradicional", no sentido de o mais comum, como aquele constituído por imagens feitas no dia a dia da família sem uma intenção outra que não a de registrar os momentos para serem guardados como lembranças. 
do paradoxo fundamental do rastro, uma vez que um lampejo do passado sobrevive na fragilidade que 0 caracteriza: "ele é rastro porque sempre ameaçado de ser apagado ou de não ser mais reconhecido como signo de algo que assinala" (GAGNEBIN, 2012, p. 27). Assim, o rastro se diferencia da experiência aurática e ressurge como "ausência de uma presença" (GAGNEBIN, 2012, p. 27), como rasura, como ruína ${ }^{6}$.

Ao restringir enormemente 0 recurso aos arquivos como forma de figurar as memórias, e também por esses cobrirem não uma voz off confessional e memorialística, mas uma conversa (no caso da foto dos irmãos) e uma trilha sonora (no caso dos arquivos policiais), Cristiano acaba inscrevendo fortemente esses arquivos no presente e deflagrando com tal gesto a impossibilidade de volta ao passado, a impossibilidade de ter o passado nas mãos. É como se 0 cinema devesse, ou só pudesse, ser tão real como a própria vida, e sua capacidade fantasmática, de reviver o irmão morto, fosse relegada ao terreno do ilusionismo, de um faz de conta que o cinema inventa para as ficções e que para aquela história não faz nenhum sentido. Contra o espetáculo cinematográfico, resta a experiência, "o tempo vivido", diria Comolli (2007), ou suas ruínas.

\section{Alteridade ou as potências do documentário}

Em Mataram meu irmão, o traço do documentário é o mais incisivo. 0 filme é todo ele o presente da filmagem onde as memórias viram atos de fala. $0 \mathrm{~s}$ entrevistados têm longo tempo para serem ouvidos. Vemos suas expressões mudarem, o choro surgir, os vazios da memória. Ainda que os personagens estejam ali pela história da morte de Rafael, eles ganham uma existência própria? 0 primo, companheiro no uso das drogas e nos pequenos furtos, relata sua experiência no Capão Redondo, suas internações e dificuldades com 0 vício. A irmã lembra que iria fazer quinze anos dois dias depois da morte do irmão e que foi poupada das informações sobre 0 assassinato, e chora a falta dos sobrinhos. A filha de Rafael toca em um violão rosa as músicas que a faz lembrar o pai. Não é apenas a história do assassinato de um parente querido que une essas pessoas, mas também o sentimento de reviver esse momento e de se instaurar por algum tempo ali, no espaço das memórias, e da dor, que 0 documentário, ele mesmo, provoca.

Flávia também utiliza várias entrevistas, porém elas aparecem informando a história de Celso

"As ruínas contrariam o devir abstrato do tempo, compensando a sistemática tripartição - antes, durante, depois - pela dinâmica pas encore (ainda não) e jamais plus (nunca mais). (...) Instante único, elas atestam um tempo antes do qual nada foi consumado e depois do qual tudo está perdido"(MATOS, 1998, p. 83).

Com essa ideia de existência própria, pensamos aqui na noção de documentário em Comolli, na qual os sujeitos filmados se tornam únicos através da relação com o cinema: "0 que acontece com aqueles que filmamos, homens ou mulheres, que se tornam, assim, personagens de filme? Eles nos atraem e nos retêm, antes de tudo porque existem fora do nosso projeto de filme" (COMOLLI, 2008, p. 175). 
que a diretora conduz pela narração em off, e preenchendo as lacunas de suas memórias de infância. 0s parentes, amigos e personagens envolvidos no crime são solicitados pela cineasta a falar, muitas vezes a partir de cartas ou fotos, questões específicas que estão em aberto na investigação ou na recomposição da trajetória familiar. Já a mãe e 0 irmão Joca, para além das entrevistas, atuam no processo de construção do filme. A mãe está presente em quase todas as revisitações aos lugares onde a família morou durante 0 exílio, se fazendo personagem da busca junto com Flávia. Joca, que interpreta a voz do pai nas leituras das cartas, é também aquele que interroga 0 filme de dentro, compondo um personagem ora deslocado ora tensionador do processo. Descrente da investigação que a irmã conduz sobre a situação real da morte do pai, ele confessa 0 incômodo em se sentir ao mesmo tempo dentro e fora do filme. Se seu ceticismo aponta, por um lado, para o fracasso de um projeto de filme que corresponderia à busca por uma verdade perdida, por outro, tal descrença só se erige em função de uma crença anterior no poder do cinema em revelar um mistério do passado, no poder da imagem como revelação. É na operação mesma do filme, ali onde ela questiona 0 que pode 0 cinema, que os irmãos se separam, o pai se divide, e a lida com a morte se mostra como uma entre tantas possíveis. Flávia reconhece as impotências do cinema e aposta no filme, Joca reconhece a impotência do filme e aposta no cinema.
Em Elena, além da própria cineasta, a principal personagem da mise-en-scène no presente do filme é a mãe. Ela aparece atuando em um trecho do filme que fizera ainda jovem, no trajeto de revisitação ao prédio onde a filha morrera, nos vídeos e fotos caseiros. Além do depoimento de um amigo americano, a mãe é a única entrevistada, e a única, além da cineasta, que fala de suas memórias, da vida e do suicídio de Elena. Contudo, nessas entrevistas, a dor pela ausência da filha é menos um sentimento que surge no processo, nos atos de busca e de fala, do que um efeito de reencenação dela mesma. Enquanto fala, a mãe encena as situações, deita no sofá para mostrar a forma como Elena estava quando a encontrou morta no apartamento, faz gestos eloquentes aperta as mãos contra o peito e segura a cabeça - para dizer das dores da saudade e do sentimento de culpa, fala de suas memórias deitada, de olhos fechados, em close, e encena junto com Petra e outras mulheres a cena final.

De maneira diferente dos arquivos, 0 recurso das entrevistas, dos encontros com parentes e amigos, das visitações aos lugares onde os parentes mortos moraram ou estiveram, é como atos de busca que definem o caráter processual dos filmes. Essas ações que reconstroem uma experiência passada no presente da filmagem através do envolvimento de outros podem levar assim - como sugere Bernardet (2006: 27) em sua leitura dos Catadores e eu (2000), de Agnès Varda - à possibilidade de se entrever a dimensão alter do eu que narra, atua e dirige. Trata-se da potência do gesto do 
documentário em abrir a escrita pessoal, suas memórias e confissões, para um fora. Porém, Bernardet chama a atenção para uma outra característica comum a esse cinema em primeira pessoa, denominado "documentário de busca" pelo autor, que 0 difere dos filmes autobiográficos de, por exemplo, Jonas Mekas e David Perlov. Aquilo que chamamos aqui atos de busca são formas de reconstituição de acontecimentos anteriores, reencenações que, ao se lançarem para o passado, se convertem em narrativas e, portanto, podem exprimir a alteridade também pelas estratégias de ficcionalização que lhes são inerentes. Os familiares, o próprio cineasta, e aqui também o ente falecido se fundem em um personagem, fazendo com que a vida pessoal, familiar, se molde "com as regras da ficção" (BERNADET, 2005, p. 149).

Dependendo do modo como o mecanismo de cada filme ativa esse processo e converte a busca em narrativa, conjugando-o com o texto que rememora, a montagem dos arquivos, e fazendo deslizar ficção e documentário, a primeira pessoa ( 0 eu/cineasta/ personagem) pode se tornar mais ou menos centrado, mais ou menos opaco, pode se espalhar e se proliferar no tempo, na história, possibilitando em maior ou menor grau a passagem de uma identidade una para um eu múltiplo, o alter 8 .

Elena é o filme em que o eu que narra está mais exposto e centralizado. Não apenas em função das inúmeras imagens de arquivo nas quais a cineasta aparece, da direção das interpretações, e das cenas em que ela passeia pelas ruas de Nova York, mas, principalmente, pela condução da narrativa após a morte da irmã quando a diretora assume 0 protagonismo das cenas e se filma inúmeras vezes: o rosto bem de perto, em close, pensativa, dançando no teatro e na rua. Na verdade, 0 filme faz um jogo de duplicidade entre ela e a irmã, como se ambas se confundissem (por isso afirmamos que Petra interpreta a si mesmo e Elena). A semelhança física e da voz favorece essa duplicidade, que, em alguns momentos, inclui a mãe (que aparece jovem no filme), perfazendo uma triplicidade. No entanto, ao contrário de marcar a separação entre elas, e ressaltar a dimensão alter do eu que narra, essa duplicidade acaba por colar as histórias, ultrapassando as diferenças.

Em Diário de uma busca, apesar do controle das entrevistas, Flávia descentraliza a figura do eu

"Não me agrada que as pessoas falem em 'identidade sexual', 'identidade nacional', 'identidade cultural' etc. Porque elas confundem identidade com pertencimento. Assim, quando falam, em identidade brasileira, francesa, confundem o que seja identidade - 'A' idêntico a 'A', isto é, 'Michel Serres' é idêntico a 'Michel Serres': isto é a identidade. 0 fato que ele seja francês... Isso não é a minha identidade, isso é meu pertencimento. 0 fato que eu seja judeu, católico, protestante... Pertencimento. 0 fato que eu me chame Serres é, aliás, um pertencimento a uma família. 0 fato que eu me chame Michel é pertencimento ao conjunto de pessoas que se chamam Michel. Tudo isso são pertencimentos. E, por consequência, confundir pertencimento com identidade é a própria definição de racismo. Porque se diz: ele é negro, ele é judeu, ele é católico, ele é... Não! Ele é Michel Serres. A identidade não deve ser confundida com pertencimento. Uma coisa é: $A=A$ ('A' idêntico a 'A'); outra coisa é: A Î $\{A\}$ ('A' pertence ao conjunto ' $A$ '). Mas podemos ir mais longe e dizer: 'qual é sua identidade?' Minha identidade é a interseção de todos os meus pertencimentos" (SERRES, 2000, p. 139). 
confessional que narra, atua e dirige, não apenas na forma ambígua como procura compartilhar o filme com Joca, mas também em momentos específicos que 0 descontrole dos encontros é inevitável (a tia que engasga ao ler a carta, a amiga que denuncia sorrindo a solenidade do momento, o morador da casa no Chile que pergunta se o pai era uma figura importante). Além disso, no ato de se aproximar, a cineasta também se afasta do pai, principalmente pelas memórias de criança em que o mundo adulto parece se oferecer sempre como um obstáculo para 0 que é coisa de infância.

\section{Em Mataram meu irmão, Cristiano é bem mais} opaco. Seria possível até questionar o caráter autobiográfico do filme que, segundo Philippe Lejeune (2008), prescindiria da coincidência entre 0 autor/cineasta, narrador e personagem 9. Porém, ainda que 0 filme não se atenha ao registro confessional, logo no início Cristiano anuncia seu projeto pessoal quando, sobre uma tela preta, durante uma conversa ao telefone com a funcionária do Cemitério, declara seu desejo de visitar o irmão morto que lá está enterrado. Em seguida, sobre cenas noturnas do trânsito da cidade, ele confessa que jamais se esquecerá 0 dia em que soube do assassinato do irmão a tiros no Capão Redondo e das palavras da mãe que até hoje lhe atormentam. 0 cineasta relembra a última visão de Rafael fumando crack, o abalo e a culpa que sentiu. Ao citar Herman Hesse, demonstra, como nos ensina Blanchot e Lejeune ${ }^{10}$, o desejo de sinceridade que define a escrita de si: "Não é agradável minha história, não é suave e harmoniosa como as inventadas. Sabe a insensatez e a confusão, a loucura e o sonho, como a vida de todos os homens que já não querem mais mentir a si mesmo". Contudo, é interessante notar como essa dimensão pessoal, do eu que é personagem, pode se conservar na medida em que 0 filme desliza completamente para o documentário, naquilo que define uma inscrição verdadeira, 0 encontro com outro, a câmera e 0 tempo presente. Cristiano se mantém no antecampo e é dali que, timidamente, de forma bastante oblíqua, 0 personagem/cineasta se inscreve.

Na fala dos entrevistados, o cineasta é constantemente evocado junto com o irmão, "você achava que era adotado", diz 0 amigo. Ainda que ele não se manifeste, 0 antecampo é como que tensionado pra dentro da cena, fazendo coincidir a história que é contada com a história de quem

Nas palavras do autor: "Para que haja autobiografia (e, em uma perspectiva mais geral, literatura íntima) é preciso que haja relação de identidade entre 0 autor, o narrador e o personagem” (LEJEUNE, 2008, p.15).

Acerca de uma modalidade de escrita de si, o diário, Blanchot afirma: "Ninguém deve ser mais sincero do que 0 autor de um diário, e a sinceridade é a transparência que lhe permite não lançar sombras sobre a existência confinada de cada dia, à qual ele limita o cuidado da escrita" (BLANCHOT, 2005, p. 271). Lejeune fala da sinceridade do ponto de vista do leitor, aqui, espectador: "A minha expectativa não é a do consumo de um objeto imaginário: estou entregue à curiosidade, numa atitude de escuta, em relação a algo que creio ser real" (LEJEUNE, 2003, p. 50). 
escreve. No último encontro com a filha de Rafael, há como que uma implosão dessas instâncias, e 0 antecampo é invadido pela adolescente que abraça o tio a chorar do outro lado, e pelo sobrinho mais novo, até então acabrunhado nos cantos do quadro, que também o abraça longamente.

\section{História ou as potências do pessoal}

É da maior ou menor centralidade e exposição do eu que as formas de passagens de uma escrita de si para uma história coletiva irá resultar. Com certeza, a biografia do pai revolucionário traz um período importante da história política da América Latina. Essa história, em Diário de uma busca, poderia, de saída, ser maior porque consagrada, hegemônica. Todavia, mesmo em uma narrativa cronologicamente amarrada, ela surge pela memória da narradora, significada por sua experiência de criança, pela tensão com a vida dos militantes - que viajavam todo tempo, faziam reuniões e evocavam um tanto de "ismos" em suas falas -, e, ainda, pela incompreensão da adolescente que vê o pai morrer vencido por uma ordem política. É uma história que emerge do menor, da mobilização dos afetos, a exemplo daquela família ampliada aos outros filhos de exilados que se sentiam livres entre os muros de um sanatório em Buenos Aires, que lhes serviram de abrigo político.

Já em Elena a centralidade do eu que narra parece dificultar essa passagem a uma história maior, que, por sua vez, não precisaria ser também a do período da ditadura que, nesse filme, ilustra a época em que a moça nasceu. Há outra história que se insinua pela condição da mulher, das exigências sobre seu corpo, da dificuldade em se adequar às demandas do espetáculo ao mesmo tempo em que se é parte dele. Essa história figura nas poucas lacunas que sobram entre os vídeos caseiros em que Elena dança feliz, dorme delicada com a irmã ainda bebê, olha triste e distante para a câmera dizendo estar gorda, até as gravações e escritos nos quais confessa o bolo de linhas que ocupa seu corpo, impedindo que ela continue a vagar pelas ruas. Porém, o filme não deixa que 0 menor desse corpo-vídeo, corpo-arquivo, singularize o espírito maior de um tempo, que se esvai em um eu que, ao se exceder, é incapaz de sair do espetáculo para acioná-lo em uma forma histórica.

Em Mataram meu irmão, a história maior se inscreve no proliferar de Cristiano pelos parentes, na dissolução de eu no comum, e também no tempo e no espaço da periferia de São Paulo, uma região violenta e esquecida. "0 Rafael cresceu no auge do crack em São Paulo, pra começar a história...", ouvimos do amigo da família. Ele explica como a periferia é um lugar frustrante, mas insidioso, que traz o conforto de um microcosmos no qual se vive isolado do mundo lá fora. "Ninguém quer saber quem é aquele Zé Mané. É só pra você passar meia hora do seu dia assistindo a uma carnificina e fazendo seus pré-julgamentos. Pra gente, que viveu essa história, que conviveu com mortes tão estúpidas, é diferente. São figuras que ficam num álbum de retrato, na tevê eles passam 
e são instantâneos... Mas a gente sabe se aquilo que aconteceu foi justo..." Essa história, maior que Cristiano, mas menor em visibilidade, aparece impregnada nas falas dos entrevistados, como se fosse impossível separá-la do corpo deles, surgindo aqui e ali naturalmente.

0 maior, enquanto história coletiva, de um tempo pode ser 0 oficial, o que todos enxergam como tal, portanto, como igual, o que parece ser de todos porque é o mesmo, o que ocupa todos espaços porque hegemônico, e isso constrange a visão. 0 menor, enquanto história pessoal, pode ser aquilo que se ensimesma, encapsula, que não divide, que centraliza no eu. Nessa perspectiva, ambos só produzem a identidade como o idêntico. No entanto, o jogo entre o maior e o menor é bem mais complexo. 0 menor pode também ser o menos importante, 0 ordinário, o qualquer, e por isso mesmo resistir em sua singularidade ao já dado, ao oficializado, ao legitimado, e, nessa resistência, se abrir à grandeza do maior como o comum, 0 vivido em partilha, o tempo do outro, da experiência da diferença, a dimensão alter do eu. Nessa perspectiva, a identidade se constitui na diferença, ela é múltipla. 0 cinema pode não encerrar os superlativos, mas os deslocar, os matizar, de forma a dar a ver o quanto a imagem faz sobreviver o espírito de um tempo, 0 quanto o pessoal guarda de político.

\section{Referências}

BENJAMIN, Walter. Obras escolhidas, vol.1. Magia e técnica, arte e política: ensaios sobre literatura e história da cultura. São Paulo: Brasiliense, 1983.
BENJAMIN, Walter. Passagens. Belo Horizonte: Editora UFMG; São Paulo: Imprensa Oficial do Estado de São Paulo, 2006.

BERNARDET, Jean-Claude. Documentários de busca: 33 e Passaporte Húngaro. In: Mourão, M.D.; Labaki, A (orgs). 0 cinema do real. São Paulo: Cosac Naify, 2005. BERNARDET, Jean-Claude. Os catadores e eu. In: Catálogo da mostra Agnès Varda: o movimento perpétuo do olhar, CCBB, ago./set. 2006.

BLANCHOT, Maurice. 0 livro por vir. Lisboa: Relógio D'água, 1984, p. 193-198.

COMOLLI, Jean-Louis. Algumas notas em torno da montagem. Revista Devires - Cinema e

Humanidades. Belo Horizonte: Universidade Federal de Minas Gerais. Faculdade de Filosofia e Ciências Humanas (Fafich), v. 4., nº 2., 2007.

COMOLLI, Jean-Louis. Ver e poder. A inocência perdida: cinema, televisão, ficção, documentário. Belo Horizonte: Ed. UFMG, 2008.

GAGNEBIN, Jeanne Marie. Apagar os rastros, recolher os restos. IN: SEDLMAYER, Sabrina. e GINZBURG, Jaime (Orgs.) Walter Benjamin: rastro, aura e história. Belo Horizonte: Ed. UFMG, 2012, pp. 27-38.

LEJEUNE, Philippe. 0 pacto autobiográfico. Belo Horizonte: Ed. UFMG, 2008.

LEJEUNE, Philippe. Definir autobiografía. In MOURÃ0, Paula(org). Autobiografia. Autorepresentação. Lisboa: Edições Colibri, 2003.

MATOS, O. C. F. Vestígios: escritos de filosofia e crítica social. $1^{\mathrm{a}}$ ed. São Paulo: Palas Athenas, 1998.

SERRES, Michel. Novas tecnologias e sociedade pedagógica. Interface (Botucatu) [online]. 2000, vol.4, $\mathrm{n}^{0} 6$. http://www.scielo.br/pdf/icse/v4n6/13.pdf 
The smallest and the biggest Letters, Revolutions; Elena and They killed my brother in personal filmmaking: Diary,

\section{Lo menor y lo mayor en el cine personal: Diario de una búsqueda, Elena y Mataron a mi hermano}

\section{Resumen}

¿Es posible que el cine de escritura

Can personal filmmaking, devoted to a minor, domestic, familial life history, evoke a bigger, colective history of a time. This paper sprang from the interest in comprehending the way in which a cinema with autobiographical trace can make us reflect on the alter nature of self, i.e. the incorporation of otherness, of the world, and of history into self-constitution. Having in mind this tension between the subjective desire of self-construction and the encounters that characterize documentary film, we chose three recent films whose projects are somewhat similar: Diary, Letters, Revolutions (Diário de uma busca, 2011), Elena (2012), and They killed my brother (Mataram meu irmão, 2013). In all these movies the filmmaker deals with the death of a close family member and, each one on its own way, they also undergo the work of mourning in such a way that the filming process becomes the search, in the present, for a past event.

\section{Keywords}

Personal filmmaking. Archive. Otherness. History. Documentary of searching. personal, dedicado a una historia de vida menor, doméstica, familiar, evoque otra, mayor, colectiva, de un período? Este artículo nace del interés por comprender de que forma el cine de tono autobiográfico puede hacer pensar la naturaleza otra del yo, o sea, la incorporación del otro, del mundo y de la historia en la constitución de un sí. A partir de la tensión entre el deseo subjetivo de construcción de sí y los encuentros que caracterizan al documental, elegimos tres películas recientes con proyectos semejantes: Diario de una búsqueda (Diário de uma busca, 2011), Elena (2012) y Mataron a mi hermano (Mataram meu irmão, 2013). En los tres, los cineastas se enfrentan a la muerte de un pariente cercano y realizan, cada cual a su manera, el trabajo de elaboración de esas muertes, de modo de hacer del proceso de filmación una búsqueda en el presente a partir de un acontecimiento pasado.

\section{Palabras-Clave}

Cine de escritura personal. Archivo. Alteridad. Historia. Documental de búsqueda. 


\section{Expediente}

A revista E-Compós é a publicação científica em formato eletrônico da Associação Nacional dos Programas de Pós-Graduação em Comunicação (Compós). Lançada em 2004, tem como principal finalidade difundir a produção acadêmica de pesquisadores da área de Comunicação, inseridos em instituições do Brasil e do exterior.

\section{E-COMPÓS I www.e-compos.org.br I E-ISSN 1808-2599}

Revista da Associação Nacional dos Programas

de Pós-Graduação em Comunicacão.

Brasília, v.17, n.3, set./dez. 2014

A identificação das edições, a partir de 2008

passa a ser volume anual com três números.

\section{CONSELHO EDITORIAL}

Afonso Albuquerque, Universidade Federal Fluminense, Brasil Alberto Carlos Augusto Klein, Universidade Estadual de Londrina, Brasil Alex Fernando Teixeira Primo, Universidade Federal do Rio Grande do Sul, Brasil Ana Carolina Damboriarena Escosteguy, Pontifícia Universidade Católica do Rio Grande do Sul, Brasi

Ana Gruszynski, Universidade Federal do Rio Grande do Sul, Brasil Ana Silvia Lopes Davi Médola, Universidade Estadual Paulista, Brasil André Luiz Martins Lemos, Universidade Federal da Bahia, Brasi Ângela Freire Prysthon, Universidade Federal de Pernambuco, Brasil Antônio Fausto Neto, Universidade do Vale do Rio dos Sinos, Brasil Antonio Carlos Hohlfeldt, Pontifícia Universidade Católica do Rio Grande do Sul, Brasil Antonio Roberto Chiachiri Filho, Faculdade Cásper Líbero, Brasi Arlindo Ribeiro Machado, Universidade de São Paulo, Brasil Arthur Autran Franco de Sá Neto, Universidade Federal de São Carlos, Brasil Benjamim Picado, Universidade Federal Fluminense, Brasil César Geraldo Guimarães, Universidade Federal de Minas Gerais, Brasil Cristiane Freitas Gutfreind, Pontifícia Universidade Católica do Rio Grande do Sul, Brasil Denilson Lopes, Universidade Federal do Rio de Janeiro, Brasil Denize Correa Araujo, Universidade Tuiuti do Paraná, Brasil Edilson Cazeloto, Universidade Paulista, Brasil

Eduardo Vicente, Universidade de São Paulo, Brasil

Eneus Trindade, Universidade de São Paulo, Brasil

Erick Felinto de Oliveira, Universidade do Estado do Rio de Janeiro, Brasil Florence Dravet, Universidade Católica de Brasilia, Brasil

Gelson Santana, Universidade Anhembi/Morumbi, Brasi Gilson Vieira Monteiro, Universidade Federal do Amazonas, Brasil Gislene da Silva, Universidade Federal de Santa Catarina, Brasil Guillermo Orozco Gómez, Universidad de Guadalajara, México Gustavo Daudt Fischer, Universidade do Vale do Rio dos Sinos, Brasil Hector Ospina, Universidad de Manizales, Colômbia Herom Vargas, Universidade Municipal de São Caetano do Sul, Brasil leda Tucherman, Universidade Federal do Rio de Janeiro, Brasil Inês Vitorino, Universidade Federal do Ceará, Brasil Janice Caiafa, Universidade Federal do Rio de Janeiro, Brasil Jay David Bolter, Georgia Institute of Technology, Estados Unidos Jeder Silveira Janotti Junior, Universidade Federal de Pernambuco, Brasi João Freire Filho, Universidade Federal do Rio de Janeiro, Brasil John DH Downing, University of Texas at Austin, Estados Unidos
José Afonso da Silva Junior, Universidade Federal de Pernambuco, Brasil José Carlos Rodrigues, Pontifícia Universidade Católica do Rio de Janeiro, Brasil José Luiz Aidar Prado, Pontifícia Universidade Católica de São Paulo, Brasil José Luiz Warren Jardim Gomes Braga, Universidade do Vale do Rio dos Sinos, Brasil Juremir Machado da Silva, Pontifícia Universidade Católica do Rio Grande do Sul, Brasil Laan Mendes Barros, Universidade Metodista de São Paulo, Brasil Lance Strate, Fordham University, USA, Estados Unidos Lorraine Leu, University of Bristol, Grã-Bretanha Lucia Leão, Pontifícia Universidade Católica de São Paulo, Brasil Luciana Panke, Universidade Federal do Paraná, Brasil Luiz Claudio Martino, Universidade de Brasília, Brasil Malena Segura Contrera, Universidade Paulista, Brasil Márcio de Vasconcellos Serelle, Pontifícia Universidade Católica de Minas Gerais, Brasil Maria Aparecida Baccega, Universidade de São Paulo e Escola Superior de Propaganda e Marketing, Brasil Maria das Graças Pinto Coelho, Universidade Federal do Rio Grande do Norte, Brasil Maria Immacolata Vassallo de Lopes, Universidade de São Paulo, Brasil Maria Luiza Martins de Mendonça, Universidade Federal de Goiás, Brasil Mauro de Souza Ventura, Universidade Estadual Paulista, Brasil Mauro Pereira Porto, Tulane University, Estados Unidos Nilda Aparecida Jacks, Universidade Federal do Rio Grande do Sul, Brasil Paulo Roberto Gibaldi Vaz, Universidade Federal do Rio de Janeiro, Brasil Potiguara Mendes Silveira Jr, Universidade Federal de Juiz de Fora, Brasil Renato Cordeiro Gomes, Pontifícia Universidade Católica do Rio de Janeiro, Brasil Robert K Logan, University of Toronto, Canadá

Ronaldo George Helal, Universidade do Estado do Rio de Janeiro, Brasil Rosana de Lima Soares, Universidade de São Paulo, Brasi Rose Melo Rocha, Escola Superior de Propaganda e Marketing, Brasil Rossana Reguillo, Instituto de Estudos Superiores do Ocidente, México Rousiley Celi Moreira Maia, Universidade Federal de Minas Gerais, Brasi Sebastião Carlos de Morais Squirra, Universidade Metodista de São Paulo, Brasil Sebastião Guilherme Albano da Costa, Universidade Federal do Rio Grande do Norte, Brasil

Simone Maria Andrade Pereira de Sá, Universidade Federal Fluminense, Brasi Suzete Venturelli, Universidade de Brasília, Brasil

Tiago Quiroga Fausto Neto, Universidade de Brasília, Brasil

Valerio Fuenzalida Fernández, Puc-Chile, Chile

Veneza Mayora Ronsini, Universidade Federal de Santa Maria, Brasi Vera Regina Veiga França, Universidade Federal de Minas Gerais, Brasil

\section{COMISSÃO EDITORIAL}

Cristiane Freitas Gutfreind I Pontifícia Universidade Católica do Rio Grande do Sul, Brasil Irene Machado I Universidade de São Paulo, Brasil

Jorge Cardoso Filho I Universidade Federal do Recôncavo da Bahia, Brasil Universidade Federal da Bahia, Brasil

CONSULTORES AD HOC

Adriana Amaral, Universidade do Vale do Rio dos Sinos, Brasil

Alexandre Rocha da Silva, Universidade Federal do Rio Grande do Sul, Brasi

Arthur Ituassu, Pontifícia Universidade Católica do Rio de Janeiro, Brasil

Bruno Souza Leal, Universidade Federal de Minas Gerais, Brasil

Elizabeth Bastos Duarte, Universidade Federal de Santa Maria, Brasil

Francisco Paulo Jamil Marques, Universidade Federal do Ceará, Brasi

Maurício Lissovsky, Universidade Federal do Rio de Janeiro, Brasil

Suzana Kilpp, Universidade do Vale do Rio dos Sinos, Brasil

Vander Casaqui, Escola Superior de Propaganda e Marketing, Brasil

EDIÇ̃̃O DE TEXTO E RESUMOS I Press Revisão

SECRETÁRIA EXECUTIVA I Helena Stigger

EDITORAÇÃo ELETRÔNICA I Roka Estúdio
COMPÓS I www.compos.org.br

Associação Nacional dos Programas de Pós-Graduação em Comunicação

Presidente

Eduardo Morettin

Universidade de São Paulo, Brasil

eduardomorettin@usp.br

Vice-presidente

Inês Vitorino

Universidade Federal do Ceará, Brasil

ines@ufc.br

Secretária-Geral

Gislene da Silva

Universidade Federal de Santa Catarina, Brasil

gislenedasilva@gmail.com 